\title{
Inhibitory interactions among rodent taste axons
}

\author{
David R. Riddle, Stephen E. Hughes*, Carl R. Belczynski**, Charles L. DeSibour and \\ Bruce Oakley \\ Department of Biology, University of Michigan, Ann Arbor, MI $48109-1048$ (U.S.A.)
}

(Accepted 29 May 1990)

Key words: Chorda tympani; Hyperinnervation; Lateral inhibition; Lingual nerve; Regeneration; Fungiform taste bud

\begin{abstract}
The left side of the tongue of the Mongolian gerbil, Meriones unguiculatus, was experimentally innervated with both chorda tympani nerves. While this dual innervation did not increase the number or volume of fungiform taste buds on the left side, at least half of the taste buds were dually innervated since they could be neurotrophically maintained by either chorda tympani nerve. Impulse discharges occurred simultaneously in the native (left) and foreign (right) chorda tympani nerves when the taste stimulus was restricted to the left side of the tongue. The marked attenuation of the phasic or tonic portions of some taste responses suggested that dual innervation had enhanced inhibition, especially of foreign chorda tympani responses. This was confirmed when electrical stimulation of the native chorda tympani reduced the peak summated action potential discharges of the foreign chorda tympani to $\mathrm{NaCl}$ or sucrose by an average of 52 and $41 \%$, respectively. Inhibition began within seconds and continued with an 11.5-min half-life. The inhibition was unaffected by acutely disconnecting either chorda tympani nerve from the brain. We propose that dual chorda tympani innervation accentuated lateral inhibitory connections that may function normally to reduce spurious sensory signals in taste axons.
\end{abstract}

\section{INTRODUCTION}

Sensory axons branch extensively within individual fungiform papillae of frog ${ }^{5}$, albino rat ${ }^{1,3,13}$ and golden hamster ${ }^{25}$. Physiological studies indicate that a taste axon typically makes functional connections with two or more fungiform papillae in frog $^{24}$, rat $^{12}$, cat $^{18}$ and sheep ${ }^{16}$. Hence, in analogy with a motor unit, it is useful to define a 'taste sensory unit' as the primary taste axon, its multiple distal branches and functionally connected epithelial cells.

Electrical stimulation of a taste nerve $e^{4,10,14,15,23}$ or a taste papilla ${ }^{11,21}$ triggers impulses that spread antidromically and depress taste responses in frogs. Chemical stimulation of the tongue also elicits antidromic impulses that depress responses in taste sensory units. Such taste-induced antidromic impulses are a consequence of the branching of taste axons that allows ordinary taste impulses to loop back and direct a recurrent antidromic barrage toward the taste buds. These distally directed impulses can be recorded from nerve twigs ${ }^{4}$ or from fungiform papillae ${ }^{14,24}$. The simplest explanations for the brief depression of taste responses by an antidromic volley are the antidromic polarization of taste axon terminals or collisions between antidromic and orthodro- mic impulses. However, impulse collision or simple polarization of taste axon terminals fail to explain how the taste receptor cells had diminished reactivity after an antidromic volley ${ }^{10}$ or how reactivity of taste sensory units can be depressed for as long as 12-15 min after an electrical conditioning stimulus, restricted to one branch of the frog IXth nerve, laterally inhibits taste sensory units in other branches ${ }^{4,14,15}$. Gives this evidence for substantial peripheral inhibitory mechanisms in frog gustation, it is of interest to know whether similar inhibitory effects are also present in the morphologically more typical taste buds of fish and mammals. Lateral inhibition in frogs might reflect the structural peculiarities of their flat, multilayered fungiform taste buds.

Although inhibition in mammalian taste buds has not been well documented, the extensive branching of mammalian taste axons provides a natural opportunity for antidromic interactions in terminal branches that might explain previous physiological observations. For example, the firing rate of a single taste axon to stimulation of its entire receptive field averaged less than $75 \%$ of the sum of firing rates to stimulation of subportions of the axon's receptive field in cat chorda tympani nerve (ref. 18 and unpublished observations). Similarly, when taste solutions were applied to a fungiform papilla enclosed in

\footnotetext{
* Present address: Central Institute for the Deaf, St. Louis, MO, U.S.A.

** Present address: Department of Electrical Engineering, Stanford University, Stanford, CA, U.S.A.

Correspondence: B. Oakley, Department of Biology, Natural Science Building, University of Michigan, Ann Arbor, MI 48109-1048, U.S.A.
} 
a small chamber, the resulting discharges of a rat chorda tympani fiber were reduced by simultaneous chemical stimulation of neighboring papillae ${ }^{12}$.

In seeking evidence of peripheral taste inhibition in mammals, it is critical to determine whether antidromic impulses depress taste responses by inhibiting other taste sensory units or merely by reducing the excitability of antidromically invaded axonal terminals. In order to study lateral inhibition uncontaminated by antidromic invasion of axon terminals, we examined the lateral interactions between two taste nerves innervating the same part of the gerbil tongue. By shunting the right chorda-lingual nerve to the left side of the tongue we succeeded in dually innervating one side of the tongue with two chorda tympani nerves. We evaluated whether this hyperinnervation enhanced the trophic support of fungiform taste buds and accentuated the physiological responses. The results revealed exaggerated lateral inhibitory interactions among taste axons.

\section{MATERIALS AND METHODS}

Seventy-seven male and female Mongolian gerbils, Meriones unguiculatus, were used in this study. The tongues of 23 normal animals were also examined. The gerbils ranged from 6 to 29 months of age.

Surgery

Fifty-four animals, weighing between 50 and $80 \mathrm{~g}$, were anesthetized with ketamine- $\mathrm{HCl}(340 \mathrm{mg} / \mathrm{kg}$ i.m.). In experimental animals $(n=44)$ the left chorda tympani (CT) and left lingual nerves were exposed beneath the pterygoid muscles under the jaw, and the lingual nerve was transected. The combined chorda-lingual (C-L) nerve on the right side was exposed and transected where it runs superficially along the mandible before it branches and enters the tongue. The proximal stump of the right $C-L$ was crossed to the distal stump of the left lingual nerve via a 3-5 mm splice excised from the right transversus marginalis mandibulae nerve (TMM branch of cranial nerve VII). This arrangement was intended to minimize sensory fibers in the anterior two-thirds of the right side of the tongue while hyperinnervating the left side of the tongue with the left $\mathrm{CT}$ and the right $\mathrm{C}-\mathrm{L}$ nerve (Fig. 1).

In control animals $(n=10)$ the left lingual nerve was transected and a 1-2 mm piece avulsed. The right $C-L$ was also transected and a 3-5 mm piece of the right TMM spliced in between the proximal and distal stumps of the right $\mathrm{C}$-L nerve. Hence, in control animals the anterior two-thirds of the left side of the tongue was innervated by the left CT, and the right side by the regenerated right $C-L$. All suturing was done with 11-0 nylon (Ethilon).

Five to 20 months after nerve surgery one CT was interrupted in 12 of 44 experimental animals as follows: the left $C T$ was avulsed $(n=4)$, transected $(n=1)$ or crushed with fine forceps $(n=2)$ in the middle ear 3 weeks prior to sacrifice; the right CT was avulsed in the middle ear 3 weeks prior to sacrifice $(n=2)$; or the left CT was transected in the middle ear 1 week prior to sacrifice $(n=3)$.

\section{Electrophysiological recording}

Animals were prepared for electrophysiological recording 5-20 months after surgery. Anesthesia was induced with ketamine as described above and maintained with i.p. injections of sodium pentobarbital as required. A tracheal cannula was inserted. A headholder helped to support the animals in ventral recumbency on a heated platform. The use of two dissecting microscopes allowed us to visualize the right and left CT nerves in the middle ear ${ }^{9}$. A small hook in the ventral epithelium gently extended the tongue, allowing it to be observed and well contacted by flowing solutions. The right and left eletrodes were positioned by micromanipulators located on each side of the head. This arrangement allowed electrical activity to be recorded simultaneously from both CT nerves with two pairs of platinum-iridum electrodes $(50 \mu \mathrm{m}$ diameter). The active electrode touched the CT, while the indifferent electrode rested on the margin of the perforated tympanic membrane. Neural impulse activity was amplified with two Grass P15 AC preamplifiers, displayed on a dual channel osciloscope, monitored on loud-speakers, recorded on magnetic tape and summated on-line by two Grass $7 \mathrm{~B} 3 \mathrm{~A}$ summators. The summator time constant was set at $0.5 \mathrm{~s}$, full wave rectification. The summated responses, as recorded on the polygraph, represented a running average of the impulse discharges in the $\mathrm{CT}$ and were indicative of changes in the aggregate activity of gustatory axons. The peak amplitude of each summated response was measured using an Apple graphics tablet and Apple II computer. In the data analysis, responses were normalized as a percentage of the peak response to either $0.5 \mathrm{M}$ sucrose or $0.3 \mathrm{M} \mathrm{NaCl}$.

\section{Chemical stimulation}

Gravity carried flowing distilled water continually across the tongue at a rate that could be increased from 0.14 to $0.76 \mathrm{ml} / \mathrm{s}$ by elevating the funnel at the top of the flow system. Six to $12 \mathrm{ml}$ of each taste solution was applied to the tongue without interruption of fluid flow. Each taste solution was followed by a minimum of $3-4$ min of distilled water rinse of the tongue. Taste solutions included: $0.5 \mathrm{M}$ sucrose, $0.3 \mathrm{M} \mathrm{NaCl}, 0.3 \mathrm{M} \mathrm{KCl}, 0.3 \mathrm{M} \mathrm{NH} 4 \mathrm{Cl}, 0.3 \mathrm{M} \mathrm{CaCl}_{2}$, $0.01 \mathrm{M}$ quinine- $\mathrm{HCl}$ and $0.01 \mathrm{M} \mathrm{HCl}$. In addition a series of sucrose and $\mathrm{NaCl}$ concentrations were tested. They ranged from 0.001 to 1.0 $\mathrm{M}$ in one-half $\log$ molar steps. The standard stimulus was $0.5 \mathrm{M}$ sucrose, which was presented after every third or fourth taste stimulation. To localize responsive taste buds, a small drop of viscous $2.0 \mathrm{M}$ sucrose was applied locally to the left or right side of the tongue with a needle or fine paintbrush.

\section{Electrical stimulation}

With two electrophysiological set-ups we could record simultaneously from the right and left CT nerves, or, by switching one recording connection to a stimulator (Grass S8 + stimulus isolation

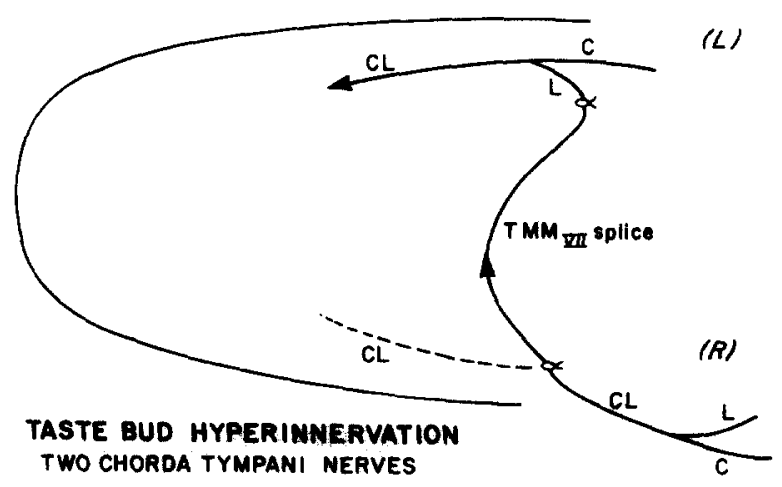

Fig. 1. The schematic view of the ventral surface of the gerbil's lower jaw indicates the nerve operations in experimental and control animals. Solid lines with arrowheads show the nerve reconnection in experimental animals in which the right chorda-lingual nerve (C-L) was shunted to the left lingual nerve using a $3-5 \mathrm{~mm}$ splice from the TMM branch of the right facial nerve (transversus marginalis mandibulae, cranial nerve VII). The dashed line indicates that in control animals a 5-mm splice of the TMM was sutured into the transected right $\mathrm{C}$ - $\mathrm{L}$ nerve whose axons were allowed to return to the right side of the tongue. Additionally, in controls 1-2 $\mathrm{mm}$ of the proximal part of the left lingual nerve was removed. 
unit/constant current unit), we could electrically stimulate one CT while recording from the other. Since we could resume recording from the stimulated nerve in $2-5 \mathrm{~s}$, we were able to look for direct effects upon the electrically stimulated CT. All stimulus parameters could be set independently for the two CTs. The values ordinarily used were: 1-3-min trains of 1-ms cathodal, square-wave pulses, of $1-4 \mathrm{~V}$ at $10-75 \mathrm{~Hz}$.

Histology

At the conclusion of the recording session, animals were sacrificed with an overdose of sodium pentobarbital, and were transcardially perfused with heparinized saline followed by a solution of $10 \%$ formalin, $15 \%$ sucrose and $1 \% \mathrm{NH}_{4} \mathrm{OH}$. All tongues were excised, kept for several days in formalin-sucrose, and embedded in paraffin. Serial, $10 \mu \mathrm{m}$, transverse sections of the anterior two-thirds of the tongue were cut and stained with Heidenhain's iron hematoxylin. Taste buds were counted by light microscopy and the position of each taste bud marked on an outline drawing of the tongue. Following the method of Cheal and Oakley ${ }^{2}$, we calculated the volume of a taste bud from its shape in the histological section that passed from apex to base through the center of the taste bud.

Plastic embedded samples ${ }^{7}$ of epithelium containing fungiform taste buds were sectioned at $1 \mu \mathrm{m}$, stained with Azure II and traced by camera lucida using an oil-immersion objective lens $(100 \times)$. We counted cell nuclei in serial $1-\mu \mathrm{m}$ sections to determine the number of cells per taste bud. The volumes of taste buds were obtained by using a computer graphics tablet to trace the area of a taste bud profile in each camera lucida drawing. For each taste bud, profile areas were summed across the $4-5$ serial, $10 \mu \mathrm{m}$, paraffin sections that encompassed the taste bud. Calculations of bud volume from its maximal profile ${ }^{2}$ or from the summation of all computer measured profile areas gave similar results.

\section{RESULTS}

\section{Anatomy}

The number of taste buds in fungiform fields supplied with two CT nerves failed to increase significantly above control levels. There were significantly more fungiform taste buds in normal animals than in operated (experimental or control) animals $(P<0.01, t$-test; Table $\mathrm{I})$. The shortage of taste buds in operated animals was primarily within the most rostral $1.5 \mathrm{~mm}$ on the tongue where a small healed scar was sometimes evident at the time of euthanasia, suggesting that animals may have bitten their tongue during the early period of partial denervation. None had feeding difficulties or chronic weight loss.

To test whether the foreign C-L would neurotrophically support taste buds, we removed the native CT in chronic experimental animals and observed $30 \pm 7$ (mean \pm 1 S.E.M., $n=4$ ) surviving fungiform taste buds on the left side. Hence, the foreign C-L supported about half of the fungiform taste buds on the left side of the tongue. The nominally denervated right side of experimental tongues had a mean of 12.5 surviving fungiform taste bud-like structures (recognized as ovoid clusters of elongated cells). These right-side taste buds were typically near the tip and midline of the tongue; they disappeared after transection of the left CT (mean = 1.5).

Dual innervation did not increase the volume of

\section{TABLE I}

\section{Number of gerbil fungiform taste buds}

Experimental animals had the left side of the anterior portion of the tongue innervated by the left chorda tympani (CT) and the right chorda-lingual (C-L) nerves. Control animals had a regenerated chorda-lingual nerve on the right side and an intact chorda tympani and interrupted lingual nerve on the left. Fungiform taste buds are predominantly in the rostral $10.0 \mathrm{~mm}$ of the tongue. Entries are means \pm 1 S.E.M.

\begin{tabular}{|c|c|c|c|c|}
\hline & Normal & $\begin{array}{l}\text { Experi- } \\
\text { mental }\end{array}$ & $\begin{array}{l}C-L \\
\text { regen. }\end{array}$ & $\begin{array}{l}C T \\
\text { only }\end{array}$ \\
\hline \multicolumn{5}{|l|}{ Left side } \\
\hline $\begin{array}{l}\text { Rostral } 10.0 \mathrm{~mm} \\
\text { Rostral } 1.5 \mathrm{~mm}\end{array}$ & $\begin{array}{r}93 \pm 2^{*} \\
48 \pm 6^{*} \\
n=12 \\
\text { gerbils }\end{array}$ & $\begin{array}{c}69 \pm 2 \\
26 \pm 2 \\
n=24\end{array}$ & $\begin{array}{c}59 \pm 19 \\
35 \pm 4 \\
n=8\end{array}$ & $\begin{array}{r}64 \pm 14 \\
25 \pm 5 \\
n=8\end{array}$ \\
\hline Right side of tongue & - & $\begin{array}{c}12.5 \pm 2 \\
n=24\end{array}$ & - & - \\
\hline $\begin{array}{l}\text { Right side after } \\
\text { removal of left CT }\end{array}$ & & $\begin{array}{l}1.5 \pm 0.6 \\
n=6\end{array}$ & - & - \\
\hline
\end{tabular}

${ }^{*} P<0.01$ with respect to each operated group $(t$-test $)$.

fungiform taste buds. There was a non-significant tendency for fungiform taste buds from experimental animals to be slightly smaller than normal fungiform taste buds. Serial $1 \mu \mathrm{m}$ sections of a limited sample of taste buds showed no significant increase in the number of cells per taste bud or in the volume of each cell (Table II).

The distribution of taste buds on the left side of dually innervated experimental tongues was quite similar to that of normal gerbils examined in the present study and in earlier studies ${ }^{2}$, except for the indicated shortfall near the tip of the tongue. Following the interruption of either the native $(n=7)$ or foreign $(n=2) \mathrm{CT}$ in a subset of chronic experimental gerbils, the fungiform taste buds that remained with one CT on the left side of the tongue had the usual continuous distribution from the tip of the tongue to the normal caudal limit of the fungiform field. For example, the spatial distribution of taste buds supported by the foreign CT alone (Fig. 2, top) is similar

\section{TABLE II}

Volume of fungiform taste buds and cells

Entries are means \pm 1 S.E.M. See Materials and Methods for volume measurements and cell counts.

\begin{tabular}{lcc}
\hline & Normal & Experimental \\
\hline Bud volume & $29,800 \pm 600 \mu \mathrm{m}^{3}$ & $27,900 \pm 400 \mu \mathrm{m}^{3}$ \\
& $(455$ buds in 8 gerbils $)$ & $(806$ buds in 7 gerbils $)$ \\
Cells/bud & $47 \pm 12 ;$ in 8 buds & $39 \pm 16$; in 9 buds \\
Cell volume & $420 \pm 130 \mu \mathrm{m}^{3} ;$ & $410 \pm 360 \mu \mathrm{m}^{3} ;$ \\
& 376 cells & 351 cells \\
\hline
\end{tabular}


to the distribution in normal animals or in a dually innervated experimental tongue (Fig. 2, bottom).

The successful dual innervation of at least half of the fungiform taste buds in experimental animals probably provided the anatomical substrate for the enhanced inhibitory responses described below.

\section{Electrophysiological responses to taste stimuli}

Simultaneous recording from the two CTs controlled for nerve differences owing to variation in stimulus delivery or state of the animal ${ }^{20}$. The massed impulse discharges and resulting summated responses were often similar in left and right CT nerves (Fig. 3). The use of a tongue chamber to restrict the taste stimulus to the rostral portion of the tongue indicated that the fungiform taste buds were responsive. By using a small paint brush to apply $2.0 \mathrm{M}$ sucrose locally to the tongue, we determined that the fungiform taste buds that activated the foreign right $\mathrm{CT}$ were on the left, not the right, side of the tongue.

\section{Apparent inhibition of taste responses with chemical stimulation}

Foreign chorda tympani nerve. We simultaneously recorded electrophysiological taste responses of the native and foreign CTs in 18 experimental animals. The summated taste responses of the foreign CT were partially reduced in 14 of 18 experimental animals tested. Although our analysis of inhibition focused on $0.3 \mathrm{M}$ $\mathrm{NaCl}$ and $0.5 \mathrm{M}$ sucrose, because their normally vigorous responses allowed the ready detection of decreases in

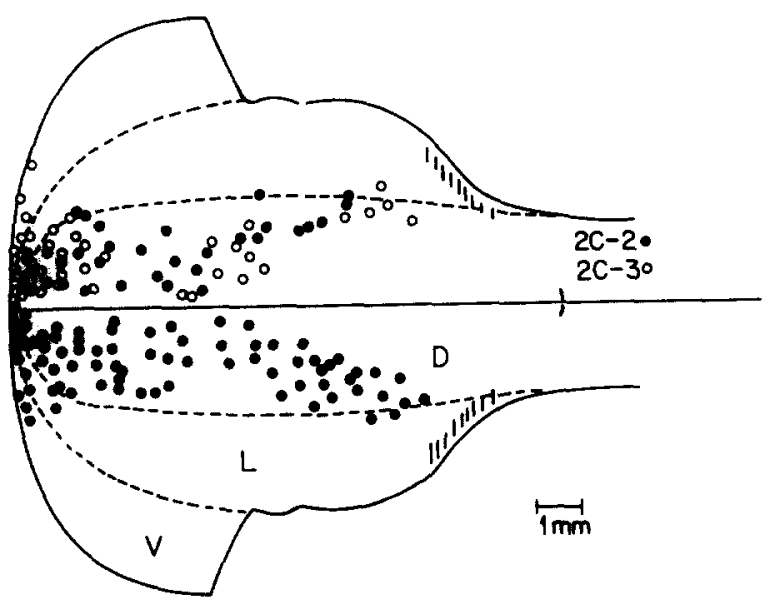

Fig. 2. The surface of the tongue has been projected onto a plane by folding out the ventral (V) and lateral (L) surfaces. D, dorsal. The lower half of the schematic shows the spatial distribution of fungiform taste buds of the left side for a typical experimental animal, while the upper half of the schematic shows data from the left side of the experimental subgroup in which the native CT had been interrupted 3 weeks prior to sacrifice leaving the foreign CT which maintained 34 and 40 taste buds in two representative animals, $2 \mathrm{C}-2$ and $2 \mathrm{C}-3$, respectively. activity, inhibitory-like effects were observed over a wide range of concentrations and to varying degree for the 5 other chemicals tested. Summated responses to $\mathrm{NaCl}$ and sucrose at several concentrations revealed 4 types of diminished taste responses. The native CT (top records in Fig. 4A-C) often had summated taste responses similar to those of normal gerbils. In contrast, responses of 6 of 14 foreign CTs had little or no phasic response - the initial activity appeared inhibited, for it increased slowly (example in Fig. 4A, bottom). This type of foreign CT response was slower to rise to peak height and slower to return to baseline. Compared to the native $\mathrm{CT}$, the rise time was markedly prolonged. The mean rise time to $90 \%$ of the maximum response was increased 8-fold (from 5.4 to $34 \mathrm{~s}$ ) for $0.5 \mathrm{M}$ sucrose and 24-fold (from 2.7 to $50 \mathrm{~s}$ ) for $0.3 \mathrm{M} \mathrm{NaCl}$ ( $n=6$ nerves). With removal of the taste stimulus by water rinse, the recovery times to $10 \%$ above baseline were about twice as long as for the native $\mathrm{CT}$. The phasic response in two of 14 experimental animals was quickly followed by a period of depressed activity prior to the tonic portions of the response (Fig. $4 B$ ). In 4 other animals of the group of 14 , there was a phasic response but little sustained tonic activity in the foreign nerve (Fig. 4C). Inhibition was generally more

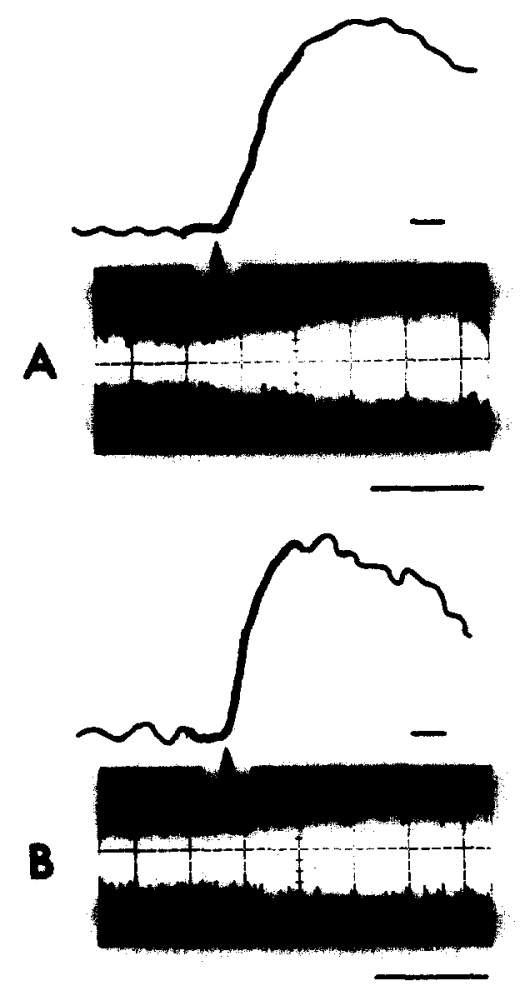

Fig. 3. The action potential discharges recorded simultaneously from the native (A) and foreign (B) chorda tympani nerves to 0.5 $M$ sucrose are compared with the electronic summation of these impulse discharges (thickened portion of the summated response). The diamonds indicate the beginning of the impulse discharge and corresponding summated responses. The time line below each of the 4 records represents $1 \mathrm{~s}$. 
A NATIVE

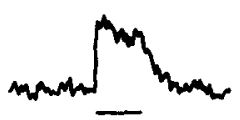

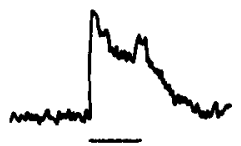

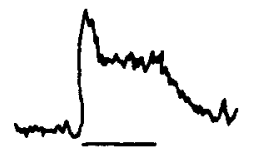<smiles>CCCCCCCCCCCCC</smiles>

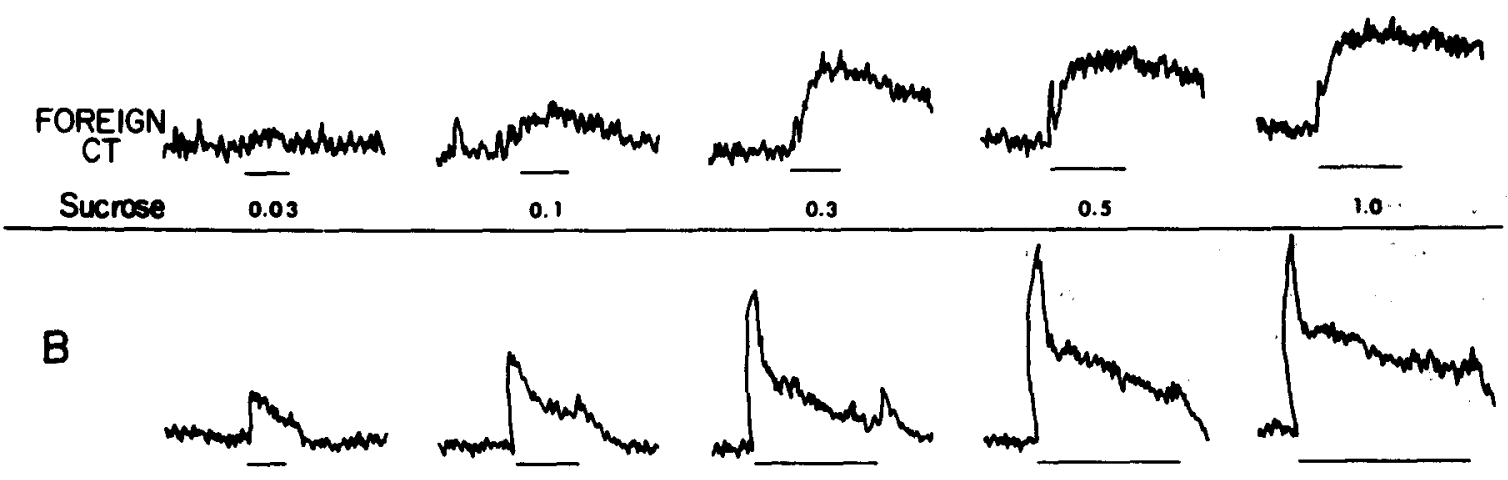

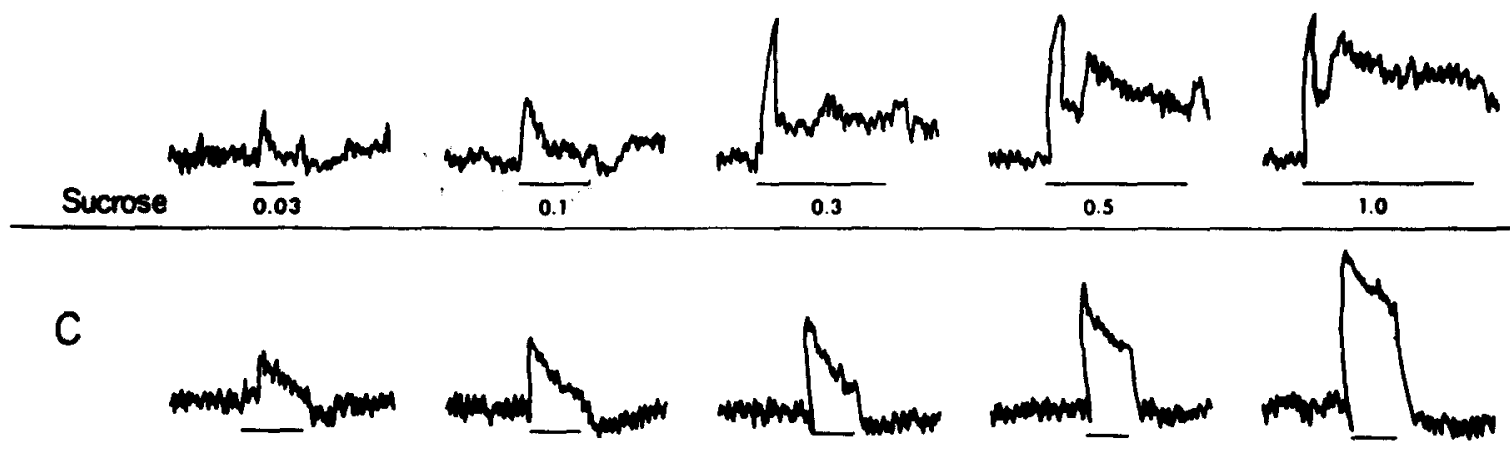

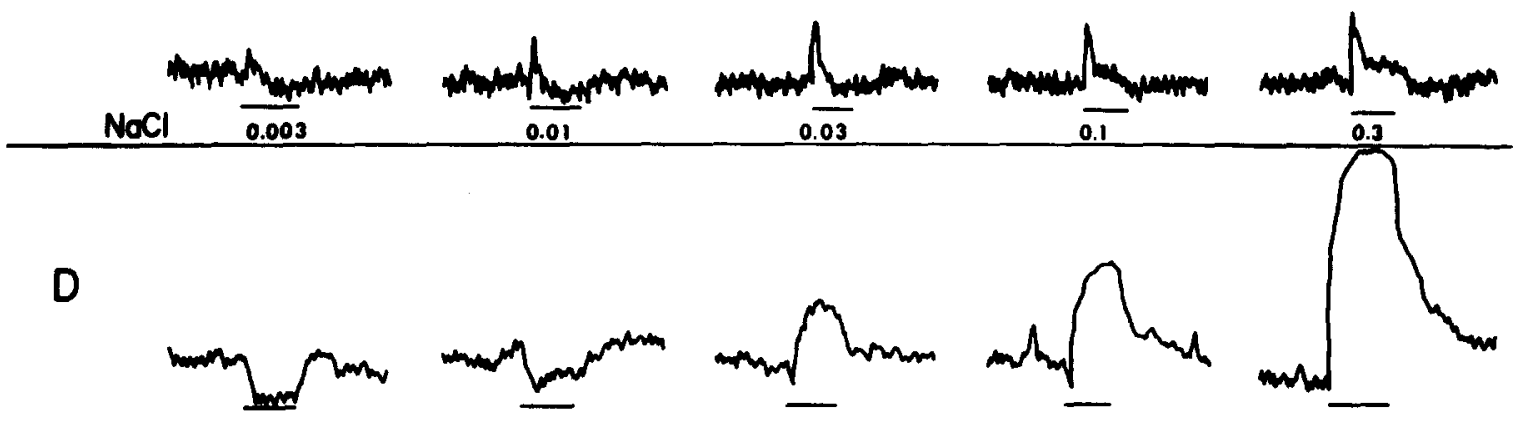

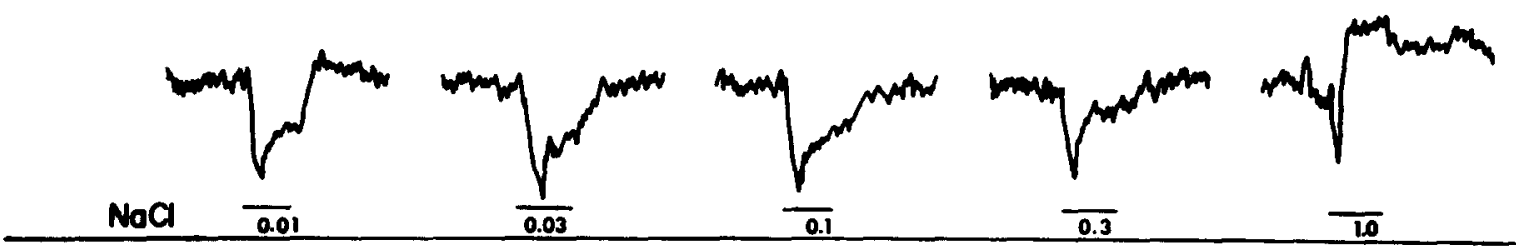

Fig. 4. Summated responses to a series of increasing molar concentrations of sucrose (A, B) and $\mathrm{NaCl}(\mathrm{C}, \mathrm{D})$ are shown as recorded simultaneously from the native and foreign chorda tympani nerves in 4 experimental animals (A-D). For each record the horizontal line shows the duration of taste stimulation. For calibration of the time scale, the length of the line under the native CT's response to $1.0 \mathrm{M}$ sucrose in the upper right of the figure is equal to $1 \mathrm{~min}$. 
pronounced at weaker concentrations, becoming less marked as the stimulus concentration was increased. In the two remaining instances of inhibition in the foreign $\mathrm{CT}$, the weaker taste solutions not only failed to elicit a response, but profoundly decreased spontaneous activity (Fig. 4D). Examination of recorded impulse activity indicated that the inhibition of summated responses to $0.3 \mathrm{M} \mathrm{NaCl}$ (Fig. 4D) resulted from sharply reduced impulse discharge frequency during taste stimulation (Fig. 5A).

To determine whether taste-induced inhibition in the foreign nerve depended upon CT overlap, we avulsed the native nerve in 4 gerbils. Three weeks later there was no indication of inhibition in the foreign $\mathrm{CT}$ taste responses in these animals. In two additional animals the native nerve was crushed 3 weeks prior to recording, thereby allowing sufficient time for axons to regenerate to the tongue $^{2}$. Inhibition was clearly evident in the foreign nerve responses in these animals. In other animals, acutely disconnecting either the native or foreign $\mathrm{CT}$ from the brain had no immediate effect on the taste response magnitude or its inhibitory features.

Native chorda tympani nerve. There was evidence for taste-induced inhibition in the responses of 6-18 native CTs. In 5 animals taste responses began with a brief reduction of discharges which increased slowly to a maximum (e.g. Fig. 5A, top). Sustained suppression of both the native nerve's response and its spontaneous activity occurred in the animal with the most markedly inhibited foreign CT responses (Fig. 4D). As a rule, signs of inhibition in the responses of the native nerve disappeared at a lower concentration than for the foreign nerve (Fig. 4D).

In summary, the overlap of foreign and native CT nerves led to the inhibition of taste responses in 14 of 18 foreign CTs tested, as revealed by a reduced phasic impulse discharge, or a reduced tonic discharge, or a reduction in spontaneous activity as well as the entire response. The inhibition of taste responses was independent of efferent signals carried from the brain by the CT nerve.

Inhibition of foreign $C T$ taste responses following electrical stimulation of the native $C T$

We found that electrical stimulation of the native CT inhibited taste responses in 11 of 12 foreign CTs tested. A typical electrical stimulus to the native nerve was a 2-min train of $1 \mathrm{~ms}, 4 \mathrm{~V}$ cathodal square waves at $10 \mathrm{~Hz}$. This depressed the foreign nerve's responses with little or no effect on the native nerve's responses. Electrical stimulation of the native CT greatly reduced the taste impulse discharge in the foreign nerve (Fig. 5C) compared with the response before electrical stimulation
(Fig. 5B). A display of the summated responses in Fig. $5 B$ and $C$ at a slower speed makes it evident that both the phasic and tonic responses were diminished in the foreign CT with no effect on the native CT response (Fig. 6A). Electrical stimulation of the native $\mathrm{CT}$ in this and other animals caused no change in the spontaneous discharge rate of the foreign $\mathrm{CT}$, (Fig. 6A, lower record). Although in these particular records the inputs to both preamplifiers were uncoupled during the 3-min period of electrical stimulation, records obtained throughout the period of electrical stimulation of the native CT showed little change in spontaneous activity of the foreign CT. The inhibition of taste responses produced by electrical stimulation of the native CT was shown to be independent of its connection with the CNS since the form and extent of diminished response were similar in tests before (Fig. 6B) and after (Fig. 6C) transecting the native CT between the stimulating electrode and the brain. Nor did electrical stimulation of the proximal nerve stump of the native CT affect the taste responses or spontaneous activity of the foreign CT.

Electrical stimulation for 1-3 min was more effective than brief pulse trains in establishing inhibition of taste responses. Although we did not make a parametric survey of the properties of effective electrical stimulation, as few as 200 pulses ( $4 \mathrm{~V}$ for $20 \mathrm{~s}$ at $10 \mathrm{~Hz}$ ) reduced the peak summated response by $25 \%$. Taste responses of the native CT were never affected by electrical stimulation of the foreign CT $(n=12)$. Likewise, in normal and control animals, electrical stimulation of one CT never affected the responses of the contralateral CT, even when the intensity of stimulation was significantly greater than that inhibiting responses of the foreign CT in experimental animals.

We made several unsuccessful attempts to lessen electrically-induced inhibition by chemically stimulating throughout the period of electrical stimulation of the native $\mathrm{CT}$, to collide orthodromic with antidromic impulses and thereby reduce the antidromic invasion of impulses into the tongue.

Among the 12 foreign CT nerves tested, there was an exact correspondence between those nerves displaying electrically induced and chemically induced inhibition. Namely, the only foreign CT nerve preparation lacking signs of chemically induced inhibition was also the only foreign CT uninhibited by electrical stimulation of the native CT. We determined further that electricallyinduced inhibition would augment chemically induced inhibition. For example, prior electrical stimulation of the native CT extended the period of reduced basal activity and abolished the moderate tonic taste response in the foreign CT (Fig. 6D).

Inhibition of the foreign $\mathrm{CT}$ response was evident with 

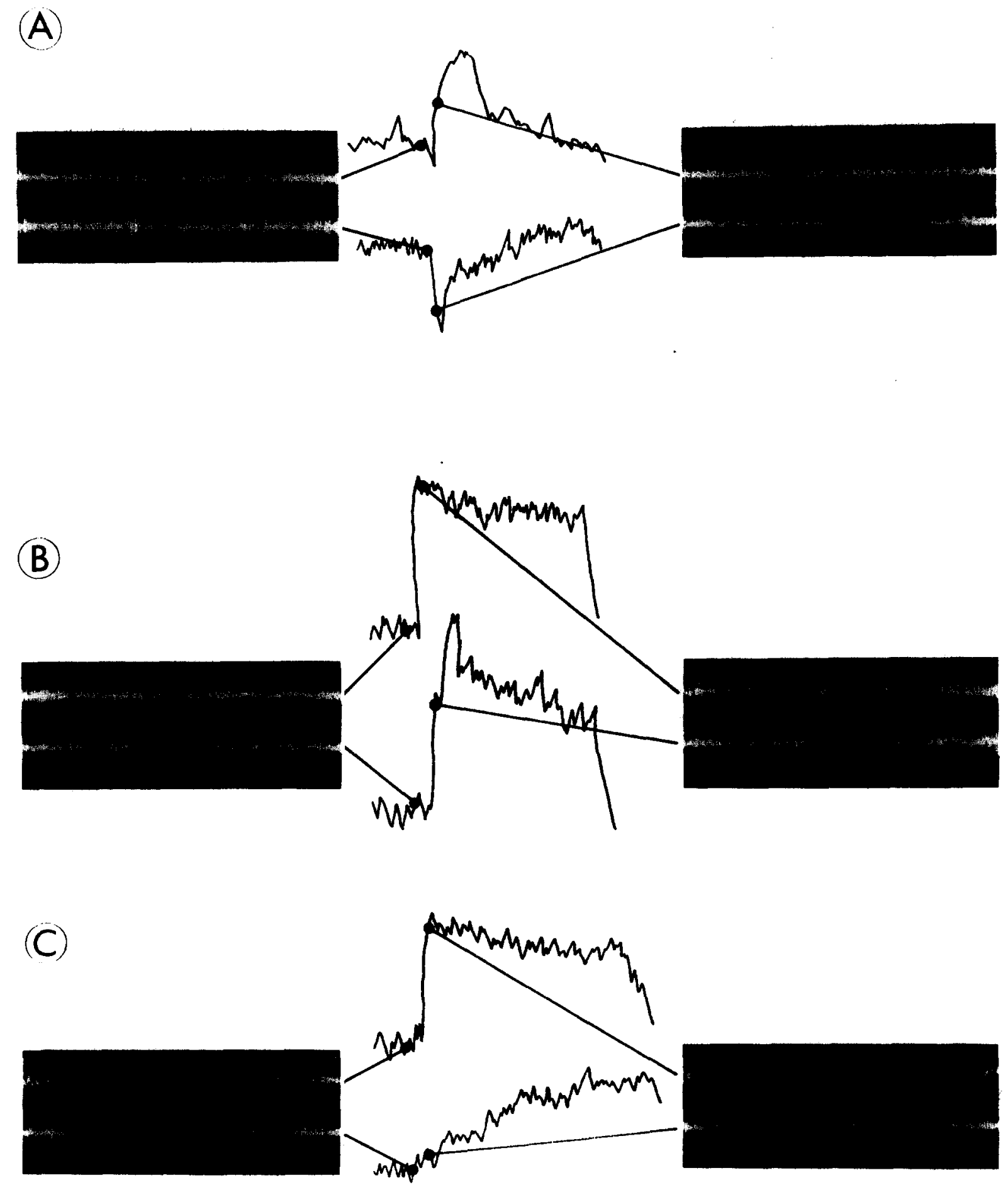

Fig. 5. In the center of A, B and C are the summated responses for the native CT (top line) and foreign CT (bottom line) with time scale expansions of the period underlying the black dots to show $0.5 \mathrm{~s}$ of actual impulse discharges. In $\mathrm{A}$, the reduction in the foreign nerve summated response to $0.5 \mathrm{M}$ sucrose corresponds to a reduction in impulse frequency. In $\mathrm{B}$, responses of both nerves to $0.1 \mathrm{M}$ sucrose began $120 \mathrm{~s}$ before electrical stimulation of the native nerve and in $\mathrm{C}, 20 \mathrm{~s}$ after electrical stimulation (1 ms monophasic square wave at $4 \mathrm{~V}$ for $3 \mathrm{~min}$ at $75 \mathrm{~Hz}$ ). The scale line in $C$ for the summated responses corresponds to $10 \mathrm{~s}$ in $\mathrm{B}$ and $\mathrm{C}$ and to $40 \mathrm{~s}$ in $\mathrm{A}$. Each pair of impulse discharge records has a $10 \mathrm{~Hz}$ time marker (dots at the top of each black rectangle).

all chemicals and concentrations tested $(0.03,0.1,0.5$ and 1.0 $\mathrm{M}$ sucrose; $0.03,0.1,0.3 \mathrm{M} \mathrm{NaCl}$ and $0.01 \mathrm{M} \mathrm{QHCl}$ ). The mean foreign $\mathrm{CT}$ phasic responses to $0.5 \mathrm{M}$ sucrose and $0.3 \mathrm{M} \mathrm{NaCl}$ were reduced by $40-50 \%$ when tested after electrical stimulation. The lack of inhibition in the CT of control animals was not due to a recovery from inhibition after $>100 \mathrm{~s}$, because the responses of the native CT of experimental animals were still well inhib- 
ited more than $200 \mathrm{~s}$ after electrical stimulation (Table III),

The time course of recovery from inhibition was evaluated in 3 animals. In spite of differences in taste stimuli, pulse frequency and the initial percentage reduction in response, the roughly parallel recovery curves suggest a similar recovery process in each animal. The mean time for the taste response to recover by $50 \%$ was $11.5 \pm 2 \mathrm{~min}$ (Fig. 7). Seventeen minutes after electrical stimulation, the response to $0.5 \mathrm{M}$ sucrose was fully recovered (sample record b in Fig. 7) from the inhibited state evident $1 \mathrm{~min}$ after electrical stimulation (sample record $a$ in Fig. 7). Moreover, the magnitude of inhibition of the foreign $\mathrm{CT}$ response $4 \mathrm{~min}$ after electrical stimulation of the native $\mathrm{CT}$ was unaffected by discon-
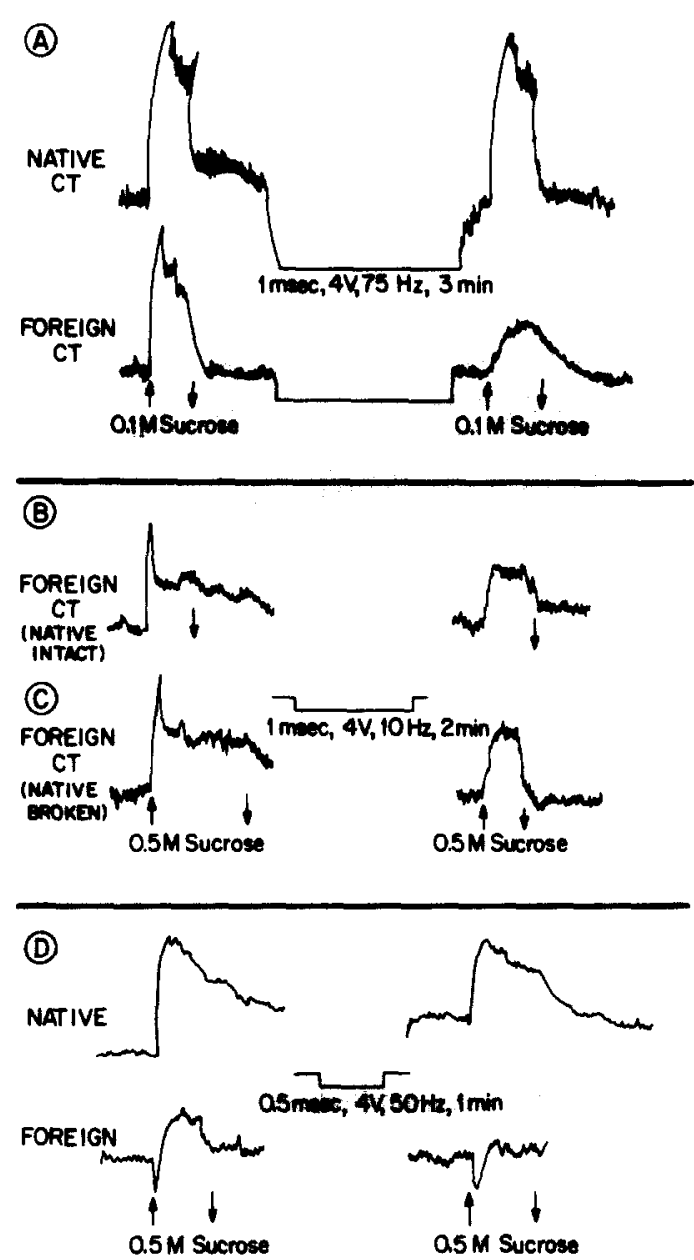

Fig. 6. Electrical stimulation of the native chorda tympani nerve reduced the responses to taste solutions in the foreign CT but not the native CT. The arrows indicate the onset of the stimulus and of the water rinse. A: electrical stimulation of the native $\mathrm{CT}$ inhibited the response of the foreign CT to $0.1 \mathrm{M}$ sucrose. The records from the native and foreign CTs were obtained simultaneously. Electrical stimulation of the native CT inhibits the response of the foreign nerve similarly before (B) and after (C) the native CT was disconnected from the CNS. In D it is evident that the inhibition already present in the foreign CT was augmented after electrical stimulation of the native $\mathrm{CT}$.

\section{TABLE III}

\section{Neural inhibition of chorda tympani responses}

Summated taste responses were recorded from the nerves shown at the left. Tabulated values are the percentage change in the summated taste responses after electrical stimulation of the chorda tympani in the contralateral ear, except for the native nerve which was itself stimulated (all at $1 \mathrm{~ms}, 1-4-\mathrm{V}$ square-wave pulses, at 10-75 $\mathrm{Hz}$ for 1-3 min). In control animals the right side of the tongue was innervated by the regenerated chorda-lingual nerve (Regen. C-L), and the left side by the chorda tympani after the lingual nerve had been transected (CT $(-L)$ ). Phasic responses were the peak height of the summated response; tonic responses were the steady-state activty 40-60 s after the onset of the taste response. Stimulation of the foreign CT had no effect on responses of the native CT (data not shown). The number of animals $(n)$ and the mean interval in seconds (s) between electrical and chemical stimulation are given.

\begin{tabular}{cccccc}
\hline & \multicolumn{2}{l}{$0.5 \mathrm{M}$ Sucrose } & \multicolumn{2}{l}{$0.3 \mathrm{M} \mathrm{NaCl}$} \\
\cline { 2 - 3 } \cline { 5 - 6 } & Phasic & Tonic & & Phasic & Tonic \\
\hline Foreign & $-41 \pm 25 \%^{* *}$ & $-32 \pm 20 \% * *$ & $-52 \pm 41 \% *$ & $-23 \pm 44 \%$ \\
& $n=7,216 \mathrm{~s}$ & $n=7,256 \mathrm{~s}$ & $n=6,217 \mathrm{~s}$ & $n=4,232 \mathrm{~s}$ \\
Native & $2 \pm 16 \%$ & $10 \pm 19 \%$ & $17 \pm 31 \%$ & $33 \pm 30 \%$ \\
& $n=4,377 \mathrm{~s}$ & $n=3,371 \mathrm{~s}$ & $n=4,367 \mathrm{~s}$ & $n=2,294 \mathrm{~s}$ \\
Regen. & & & & \\
C-L & $-5 \pm 5 \%$ & $-2 \pm 8 \%$ & $-3 \pm 5 \%$ & $1 \pm 3 \%$ \\
CT (-L) & $n=4,91 \mathrm{~s}$ & $n=4,131 \mathrm{~s}$ & $n=5,127 \mathrm{~s}$ & $n=5,167 \mathrm{~s}$ \\
& $-1 \pm 5 \%$ & $3 \pm 7 \%$ & $2 \pm 7 \%$ & $2 \pm 6 \%$ \\
& $n=4,91 \mathrm{~s}$ & $n=4,131 \mathrm{~s}$ & $n=4,84 \mathrm{~s}$ & $n=4,124 \mathrm{~s}$ \\
\hline
\end{tabular}

${ }^{*} P<0.02$ and ${ }^{* *} P<0.01$ indicate significant reductions in the responses of the foreign CT ( $t$-tests).

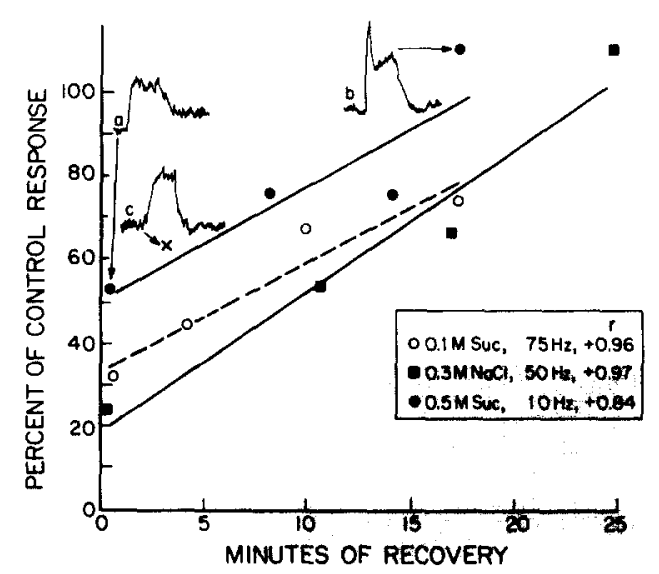

Fig. 7. The recovery of foreign $\mathrm{CT}$ taste responses inhibited by electrical stimulation of the native $\mathrm{CT}$ is shown for 3 experimental animals. The magnitude of the summated taste response is plotted as a percentage of the peak summated response immediately preceding electrical stimulation. The electrical stimulus applied to the native nerve was a 2 -min train of $4-\mathrm{V}$, monophasic square waves, of $1 \mathrm{~ms}$ duration. The key shows the stimulus pulse frequency ( 75 , 50 or $10 \mathrm{~Hz})$, the chemical stimulus $(0.1 \mathrm{M}$ sucrose, $0.3 \mathrm{M} \mathrm{NaCl}$ or $0.5 \mathrm{M}$ sucrose), and the Pearson correlation coefficient $(r)$ for the least squares best-fit straight lines. Sample records showing inhibition (a) and recovery (b) are provided for the top curve. Disconnecting the native CT from the brain did not alter the magnitude of the inhibition observed $10 \mathrm{~min}$ later with $0.5 \mathrm{M}$ sucrose - record $\mathrm{c}$ at data point $\mathrm{x}$. 
TABLE IV

Peak summated taste responses of 5 chorda tympani nerves

The following chorda tympani (CT) nerves were examined: normal $(n=15)$; native, left CT in experimental animals $(n=11)$; foreign, right CT in experimental animals $(n=11)$; control left, CT $(n=8)$; and control regen. right CT $(n=8)$. All responses to the indicated molar concentrations are relative to the responses to $0.3 \mathrm{M} \mathrm{NaCl}$ set at 100. Entries are means \pm 1 S.E.M.

\begin{tabular}{lcclllll}
\hline & $\mathrm{NaClO} 0.3 \mathrm{M}$ & Sucrose $0.5 \mathrm{M}$ & $\mathrm{KClO} 0.3 \mathrm{M}$ & $\mathrm{NH}_{4} \mathrm{ClO} 0.3 \mathrm{M}$ & $\mathrm{HClO} 0.01 \mathrm{M}$ & $\mathrm{QUIO} 0.01 \mathrm{M}$ & $\mathrm{CaCl}_{2} \mathrm{O} .3 \mathrm{M}$ \\
\hline Normal & 100 & $95 \pm 17$ & $47 \pm 23$ & $75 \pm 25$ & $59 \pm 28$ & $34 \pm 10$ & $88 \pm 38$ \\
Native & 100 & $85 \pm 18^{*}$ & $56 \pm 13$ & $77 \pm 18$ & $42 \pm 17$ & $38 \pm 19$ & $67 \pm 19$ \\
Foreign & 100 & $118 \pm 27$ & $54 \pm 12$ & $72 \pm 26$ & $51 \pm 29$ & $48 \pm 21$ & $74 \pm 30$ \\
Control left & 100 & $100 \pm 11$ & $46 \pm 15$ & $76 \pm 25$ & $45 \pm 21$ & $30 \pm 12$ & $72 \pm 26$ \\
Control regen. right & 100 & $95 \pm 26$ & $31 \pm 17$ & $61 \pm 18$ & $49 \pm 22$ & $35 \pm 15$ & $73 \pm 31$ \\
\hline
\end{tabular}

${ }^{*} P<0.005$ with respect to the foreign CT sucrose response and $P<0.05$ with respect to the control left $\mathrm{CT}$ sucrose response.

necting the native nerve from the brain. That is, the response magnitude (data point $\times$ from record $c$ ) was almost on the best-fit line generated with the CTs intact (filled circles, in Fig. 7). We concluded that central circuitry did not contribute to chemically or electrically induced inhibition of chorda tympani taste discharges.

The relative peak response magnitudes to test chemicals are shown in Table IV for the normal CT, native and foreign CTs and the two types of control CTs. Of the 5 nerves, the native nerve had the lowest relative response to sucrose; it was significantly lower than the foreign nerve's sucrose response (Table IV; $P<0.005, t$-test). This may represent a real reduction in the native nerve's sucrose response. Alternatively, because the responses in Table IV are normalized to $0.3 \mathrm{M} \mathrm{NaCl}$, a low sucrose response of the native nerve might reflect an increased response to the standard $0.3 \mathrm{M} \mathrm{NaCl}$. However, using $\mathrm{NaCl}$ as the standard (Table IV) produced no generalized lowering of native nerve responses to other chemicals $(P$ $>0.5$, binomial), as would be expected had the $\mathrm{NaCl}$ response markedly increased. A further argument that the native CT's sucrose response was low is that normalizing to the $0.5 \mathrm{M}$ sucrose response so increased the native CT's relative responses, that the response to each of the 6 other chemicals exceeded the corresponding responses of the 3 operated nerves (18 of 18 pair comparisons with foreign and two control CTs in Table IV; $P=0.000008$, two-tailed binomial test). The sucrose response of the native nerve was apparently lowered by specific interactions with the foreign $\mathrm{CT}$, rather than by lingual nerve removal or more general effects of nerve operations, since the sucrose response of the native CT was also significantly less than that of the control left CT $(P<0.05, t$-test $)$.

There were no significant differences among the 5 types of CT in least squares best fit plots of peak summated responses as a function of log molar sucrose or $\mathrm{NaCl}$ concentration (curves not shown). (Pearson $r$ values ranged from +0.95 to 0.99 .) Nor did these data provide evidence for altered numbers of binding sites or for major shifts in the apparent binding constant $\left(K_{d}\right)$ for $\mathrm{NaCl}$ or sucrose.

\section{DISCUSSION}

\section{Innervation and taste bud anatomy}

One or more of the following factors may have contributed to the loss of fungiform taste buds in experimental and control gerbils. (1) In operated control animals surgical damage to taste axons may have reduced the numbers of taste buds. (2) The greatest shortage of taste buds was at the tip of the tongue, which is the region most likely to have been damaged by uncoordinated chewing. (3) There was some evidence that foreign taste axons may have interfered with fungiform taste bud support, since the number of taste buds on the left side rose to nearly normal levels 3 weeks after removal of the cross-innervating foreign C-L ( 80 and 83 taste buds in two animals).

Dual innervation failed to increase the number of taste cells or the number or volume of fungiform taste buds. This is consistent with the view that the fungiform gustatory epithelium normally has maximal numbers of taste buds and taste cells, whereas the surrounding epithelium is not competent to form taste buds. Regarding the issue of epithelial competency, entry of the foreign $\mathrm{CT}$ via the lingual nerve stump directed taste axons into the lingual field and provided an opportunity for novel taste buds to develop in the perimeter of fungiform papillae and the interpapillary epithelium ${ }^{2,3}$. Yet the absence of taste buds in novel sites and the presence of fewer, not more, taste buds after dual innervation argue against the existence of taste-competent basal cells in the ordinary lingual epithelium. This agrees with earlier observations that the neurotrophic consequences of chorda tympani regeneration via the distal stump of the lingual nerve were indistinguishable from simple regeneration of the transected chorda tympani ${ }^{17}$. 
The fungiform taste bud population must have received dual gustatory innervation, since both CTs responded to a droplet of $2.0 \mathrm{M}$ sucrose restricted to the left side of the tongue. Within this population individual taste buds must also have been innervated by both CTs, since the foreign CT maintained half of the fungiform taste buds supported by the native CT on the left side of the tongue. As discussed below, the rapid and pronounced suppression of foreign CT taste responses by electrical stimulation of the native CT also suggests functional overlap of the two CTs in the tongue.

\section{Electrophysiological responses to taste solutions}

Use of the intact CT where it traverses the gerbil middle ear ${ }^{9}$, reduces the likelihood of deterioration in taste responses that can occur after nerve transection ${ }^{20}$. In the present study it was feasible to record simultaneously from the intact left and right CT nerves to control for the state of the organism and trial-to-trial fluctuations in stimulus delivery. Since estimates of the binding properties of taste cells for sucrose were relatively unaffected by dual innervation, the putative reduction in the native CT's peak response to sucrose may have resulted either from lateral inhibitory influences by foreign CT axons or from competition with foreign CT axons for the available supply of sucrose reactive receptor cells.

After dual innervation it was common for a CT to become deficient in initiating or sustaining taste responses. Two-thirds of the foreign nerves and one-third of the native nerves examined for taste-induced inhibition showed a reduction in either or both the phasic and tonic responses to sucrose or $\mathrm{NaCl}$. A still more marked electrophysiological indication of inhibition was the profound and sustained reduction in foreign CT responses after electrical stimulation of the native CT.

We consider 3 mechanisms of inhibition: efferent fibers, antidromic impulse activity within a taste sensory unit and lateral inhibition among taste sensory units.

It seems unlikely that efferent fibers were responsible for reducing taste responses. Vasomotor ischemia, in particular, is unlikely to be important because: (1) taste-induced inhibition in foreign CTs was often evident as soon as the taste solution was applied, even after the foreign CT had been disconnected from the CNS; and (2) electrically induced inhibition had a latency shorter than $20 \mathrm{~s}$, whereas more than $0.5 \mathrm{~min}$ of circulatory collapse is required for taste response failure in normal animals (data not shown). Further, taste-induced inhibition was frequently more pronounced in, and electrically-induced inhibition always restricted to, taste responses of the foreign CT, even though the axon terminals of the two CTs must have shared a common microcirculatory bed within jointly innervated fungiform papillae. These observations make actions of efferent fibers, such as vasomotor constriction and ischemia, unpromising explanations of inhibition.

Alternatively, antidromic impulses might suppress taste responses within a taste sensory unit. Taste axons branch distally and innervate several cells in taste buds that have similar responses to a panel of taste solutions ${ }^{18}$. When the tongue is flooded with a taste solution, impulse traffic arising from the most responsive receptor cells should travel distally into other branches of the parent axon, causing antidromic collisions and suppression of activity arising from the less active receptor cells of the taste sensory unit. If antidromic impulses from the most responsive taste cells curtail input from the least responsive cells, the inhibitory effects might be transparent to an observer monitoring the parent axon.

By innervating the left side of the tongue with two chorda tympani nerves we were able to demonstrate the critical importance of the lateral overlap of taste sensory units. In normal or control animals electrical stimulation of one CT never inhibited contralateral CT taste responses. Three weeks after removal of nerve overlap by interruption of the native $\mathrm{CT}$ in chronic experimental gerbils, the foreign CT had ceased to show taste-induced inhibition. (Since the native CT had degenerated, it was not available to test the effects of electrical stimulation.) In dually innervated tongues, electrical stimulation of the native CT profoundly inhibited taste responses in more than $90 \%$ of foreign $\mathrm{CT}$ nerves. It is not surprising that electrically induced inhibition was more effective than taste-induced inhibition, for the former can only be demonstrated with the concurrent activation of tasteinduced inhibition and is implemented by many more axons and impulses than is taste-induced inhibition. Murayama also observed that taste stimulation failed to cause potent inhibition and failed to block concurrent electrically-induced inhibition ${ }^{14}$. He found that tasteinduced inhibition only lasted for $4-6 \mathrm{~s}$ vs $>5 \mathrm{~min}$ for electrically induced inhibition. Hence, in the present work it is probable that normal inhibitory interactions were augmented when CT overlap increased the number of lateral collaterals. Two results suggest that tasteinduced and electrically-induced inhibition could utilize a common inhibitory mechanism. First, it is unlikely that by chance the same 11 of 12 gerbils that showed electrically induced inhibition were the same 11 showing taste-induced inhibition ( $P=0.007$, binomial). Second, electrical stimulation accentuated the characteristics of ongoing taste-induced inhibition (Fig. 6D).

There is little information on the anatomical site of lateral inhibitory influences. Because spontaneous activity was unaffected by electrically induced inhibition, the 
native $\mathrm{CT}$ probably inhibited foreign taste sensory units at a site distal to the site that generates spontaneous activity. The site that generates spontaneous activity is unknown, but since the spontaneous activity of taste fibers has an irregular pattern, the synapse or taste receptor cell are reasonable sites. Accordingly, the ingrowth of foreign CT axons may have resulted in inhibitory lateral branches from the native CT axons to the receptor cells of the foreign taste sensory units, with fewer or less effective reciprocal lateral connections from the foreign CT axons to native CT sensory units. The foreign CT provided sustaining innervation only to half of the taste buds. If the native CT alone innervated the remaining taste buds, it would help account for the relative immunity of the native $\mathrm{CT}$ to lateral inhibition via the foreign $\mathrm{CT}$. In summary, the electrically induced taste inhibition can be accounted for by native CT lateral collaterals that made inhibitory contacts on foreign CT sensory units, at sites predominantly distal to the site where spontaneous activity arises.

In normally innervated tongues taste inhibition may be cryptic. Yet, examples of inhibitory interludes are observed during summated responses to sugars from normal $\mathrm{CTs}^{18,19}$. Such inhibitory interludes in mammals are manifested as a temporary, marked decrease in a taste response even though the taste stimulation continues unabated (e.g. Fig. 4B, bottom). In frogs electrical stimulation of the entire IXth nerve depressed that IXth nerve's taste responses for as long as $12-15 \min ^{4,15}$. This might reflect actions of lateral inhibitory connections. But since the recordings were taken from the electrically stimulated nerve, one cannot rule out confounding effects of antidromic invasion of afferent terminals. The present experimental design utilized overlapping CT nerves to provide unconfounded evidence that inhibitory interactions can occur between mammalian taste sensory units. Since Murayama ${ }^{14}$ has recently shown in the frog that

\section{REFERENCES}

1 Beidler, L.M., Innervation of rat fungiform papilla. In C. Pfaffmann, (Ed.), Olfaction and Taste, Rockefeller Univ. Press, New York, 1969, pp. 352-369.

2 Cheal, M.L. and Oakley, B., Regeneration of fungiform taste buds: temporal and spatial characteristics, J. Comp. Neurol., 172 (1977) 602-606.

3 Farbman, A.I. and Hellekant, G., Quantitative analyses of the fiber population in rat chorda tympani nerves and fungiform papillae, Am. J. Anat., 153 (1978) 509-521.

4 Filin, V.A. and Esakov, A.I., Interactions between taste receptors, Bull. Exp. Biol. Med., (Engl. transl.), 65 (1968) 9-11.

5 Graziadei, P.P.C. and DeHan, R.S., The ultrastructure of frogs taste organs, Acta Anat., 80 (1971) 563-603.

6 Hellekant, G., Postexcitatory depression of gustatory receptors, Acta Physiol. Scand., 74 (1968) 1-9.

7 Hughes, S.E., Sloan, H.E., Jones, L.B. and Oakley, B., Colchicine reduces myelin thickness and axoplasm volume, electrically stimulating one branch of the IXth nerve depresses responses for $5 \mathrm{~min}$ in another branch of the IXth nerve, the inhibitory interactions between two CTs may be exaggerated manifestations of inhibitory interactions normally present in vertebrate taste systems.

We now briefly consider the significance for sensory coding of recurrent axonal branches that may antidromically inhibit the same taste sensory unit, or may laterally inhibit other taste sensory units. Antidromic suppression might narrow the taste response profile of a taste sensory unit and improve the signal-to-noise ratio by reducing spontaneous activity and the weak/distorted input of aged/damaged cells. Lateral inhibition may play a role in minimizing noise that occurs in a taste axon as a result of limited receptor specificity. For example, the discharge generated by $\mathrm{NaCl}$ in an $\mathrm{NaCl}$-best fiber could laterally inhibit weaker discharges in $\mathrm{HCl}$-best fibers whose receptors were only moderately responsive to $\mathrm{NaCl}$. Hence, lateral inhibition among taste sensory units could automatically reduce spurious signals generated in less vigorously reacting sensory units. To consider another example, the impulse discharge of peripheral taste axons typically adapts during continuing taste stimulation and requires several minutes of water rinse for the recovery of taste responsiveness ${ }^{6}$. Since rodent taste receptor cell potentials show minimal adaptation ${ }^{22}$, lateral inhibition should be evaluated as a candidate cause of peripheral taste adaptation and of the slow recovery of excitability after taste stimulation. By enhancing interactions ordinarily found among taste sensory units, dual innervation of one side of the tongue with two chorda tympani nerves may have revealed lateral inhibitory interactions that are normal features of the sensory circuits of mammalian taste buds.

Acknowledgements. We are grateful for the assistance of L.H. Wu. Supported in part by NIH Grant DC00083-24.

Neurosci. Lett., 37 (1983) 181-186.

8 Jakinovich, Jr., W., Stimulation of the gerbil's gustatory receptors by disaccharides, Brain Research, 110 (1976) 481-490.

9 Jakinovich, Jr., W. and Oakley, B., Comparative gustatory responses in four species of gerbilline rodents, J. Comp. Physiol., 99 (1975) 89-101.

10 Kutyna, F.A. and Bernard, R.A., Effects of antidromic activity in gustatory nerve fibers on taste disc cells, J. Comp. Physiol., 118 (1977) 291-306.

11 Macdonald, J.A. and Brodwick, M.S., Inhibition in branched afferent neurons of the bullfrog tongue, J. Comp. Physiol., 87 (1973) 293-316.

12 Miller, Jr., I.J., Peripheral interactions among single papilla inputs to gustatory nerve fibers, J. Gen. Physiol., 57 (1971) $1-25$.

13 Miller, Jr., I.J., Branched chorda tympani neurons and interactions among taste receptors, J. Comp. Neurol., 158 (1974) 155- 166.

14 Murayama, N., Interaction among different sensory units within 
a single fungiform papilla in the frog tongue, J. Gen. Physiol. 91 (1988) 685-701.

15 Murayama, N. and Ishiko, N., Selective depressant action of antidromic impulses of gustatory nerve signals, J. Gen. Physiol., 88 (1986) 219-236.

16 Nagai, T., Mistretta, C.M. and Bradley, R.M., Developmental decrease in size of peripheral receptive fields of single chorda tympani nerve fibers and relation to increasing $\mathrm{NaCl}$ taste sensitivity, J. Neurosci., 8 (1988) 64-72.

17 Oakley, B., Reformation of taste buds by crossed sensory nerves in the rat's tongue, Acta Physiol. Scand., 79 (1970) 88-94.

18 Oakley, B., Receptive fields of cat taste fibers, Chem. Senses Flavor, 1 (1975) 431-442.

19 Oakley, B., Taste responses of human chorda tympani nerve, Chem. Senses, 10 (1985) 469-481.
20 Oakley, B., Jones, L.B. and Hosley, M.A., Decline of IXth nerve responses following nerve transection, Chem. Senses Flav., 4 (1979) 287-299.

21 Rapuzzi, G. and Casella, C., Innervation of the fungiform papillae in the frog tongue, J. Neurophysiol., 28 (1965) 154-165.

22 Sato, T., Site of gustatory neural adaptation, Brain Research, 34 (1971) 385-388.

23 Taglietti, V., Effects of antidromic impulses on frog taste receptors, Arch. Sci. Biol., 53 (1969) 226-234.

24 Taglietti V., Casella, C. and Ferrari, E., Interactions between taste receptors in the frog tongue, Pflügers Arch., 312 (1969) 139-148.

25 Whitehead, M.C., Beeman, C.S. and Kinsella, B., Distribution of taste and general sensory nerve endings in fungiform papillae of the hamster, Am. J. Anat., 173 (1985) 185-201. 